\title{
How local street networks contribute to the traffic accident occurrence: Mersin city case
}

\author{
Fikret Zorlu*®
}

\begin{abstract}
In this study, the issue of the accident frequency/occurrence in local residential streets where vehicle counts are not obtained is discussed. The accident reports received from the Ministry of Interior include fatal and injury accidents. But since the number of deadly accidents is minor, a binomial regression was not employed in the statistical analysis. This study investigates the role of morphological characteristics of the street network where main arterials are excluded in the safety of residential neighborhoods of Mersin, Turkey. Results showed that commercial and industrial uses generate more traffic than residential neighborhoods, therefore, responsible for higher rates of accidents. The number of vehicles, employment, and population increase the accident rate. Empirical model results showed that population density, street length per capita (meters), and number of intersections significantly affect accident occurrence. Number of intersections increases accident frequencies while street length per capita reduces. In contrast, the number of links, street density, link to node ratio, and average link length have no significant effect on accident occurrence. Traffic safety cannot be achieved if the street length is not proportional to the number of vehicles. In addition, street design is also a matter of efficient use of urban space.
\end{abstract}

Keywords: street pattern, traffic accidents, traffic safety, street network design, Mersin

\section{Introduction}

There is extensive literature on street network design in the urban design literature. These studies deal with a broad spectrum of network properties, street properties, network performance, the network's relationship with land use, walkability, space quality, and traffic safety. However, there are limited studies on the safety and efficiency of the street network. Empirical studies are needed to measure the network efficiency, measured by indicators such as the share of the street network in the total urban area, street length per unit population, street length coverage per unit population, and the capacity utilization rate. On the other hand, traffic volume and density data are primarily available for main urban roads and the streets in the city center. Still, it is difficult to assess street networks' traffic safety and efficiency in residential areas due to limited traffic data. Hypothetical network efficiency is evaluated using simulation models in the literature, while space syntax methods measure street network geometric features. Therefore, the number of studies investigating existing networks' traffic safety and efficiency performances is limited. 
Traffic safety studies are mostly deal with main road networks and intersections. This fact is that vehicle counts are available for main roads, and data cannot be obtained for local streets in residential areas. A few studies have examined the relationship between accident occurrence risks in street networks in residential areas and road network characteristics. Studies dealing with the spatial distribution of accidents throughout the city search for the effects of variables like population, land use, and vehicle ownership. However, in zone-based analyses, main arterials and local streets cannot be distinguished. Since vehicle counts are conducted on the section of main arterials, the effect of the street network characteristics on accident occurrence cannot be specified in zone-based studies.

In this study, the central theme is the accident in local residential streets where vehicle counts have not been obtained. The accident data are obtained from the Ministry of Interior include fatal and injury accidents. Since the number of deadly accidents is meager, a binomial regression aiming at measuring the severity of crashes was not employed in the statistical analysis. This study investigates the role of morphological characteristics of the local street network in the safety of residential neighborhoods of Mersin city, Turkey. In addition, the efficiency of street planning, which refers to the street surface and street length per unit population, is discussed.

Mersin city is located on the southern coast of Turkey and hosts one of the country's major ports. The urban population of the core city was 873,027 , while the metropolitan population was nearly one million in 2016. The research covers 85 neighborhoods in the core city, which accommodates central business district, industrial zones, free zone, port, commercial facilities, and most residential uses of the metropolitan area. In the last six decades, the city experienced a gradual economic development and a rapid increase in the population. Furthermore, increasing car ownership rates, irregular spatial development, insufficient mass transit infrastructure led to increasing traffic volumes and accidents at both significant arterials of the city and local streets of the neighborhoods. Today, traffic safety is one of the primary indicators of the wellbeing of society, and accident rates have shown that more efforts are necessary to reduce accident rates. There are limited studies on traffic safety problems in the city. The majority of those studies dealt with accidents at major arterial and intersections of the city. A limited number of studies dealt with traffic accidents in Mersin city. Özen (2020) investigated the relationship between traffic volume, intersection geometry, traffic control characteristics, and vehicular fatal/injury traffic crashes at 39 four-legged signalized intersections in the city and found that a total number of approaches increases accident frequencies while the higher ratio of traffic volumes at primary/secondary legs reduces intersection crashes. The rest of the studies investigated the roles and effects of socioeconomic factors, motorization, driver and pedestrian profile. There is a gap in the research field of traffic safety for local streets. This study focuses on local street networks and their influence on traffic safety.

\section{Literature}

The adequacy and efficiency of the street network in urban space are related to the geometric properties of the network. Kansky (1963) defined some indices to compare the geometric properties of transportation networks with quantitative indicators. The gamma index is a ratio of edges and vertices of a given network, which refers to an observed number of nodes (fringes) to the possible maximum number of nodes. The gamma index $(\gamma)$ is a ratio between 0 and 1 , where an index close to 0 indicates weak connectivity and 1 indicates strong conrobustity. Alpha index $(\alpha)$ is the ratio of the number of actual circuits in the street network to the maximum possible ones (Kansky, 1963). If the alpha index is close to 0 the network is regarded as "weak," and an index value close to 1 indicates "strong connectivity". Beta index $(\beta)$ is the node (edges) to link (vertices) is also called "node to link ratio (NLR)". In this regard, link to node ratio (LNR) $(1 / \beta)$ can be regarded as a connectivity indicator. Connected node ratio (CNR) refers to the percentage of intersections (nodes connect more than one link) to a total number of nodes, including dead ends. This ratio also 
indicates the degree of network connectivity, the higher the percentage, the higher the connectivity.

Haggett and Chorley (1969) related those indices to accessibility and efficiency levels of the street network. Litman (2005), based on the findings in the literature, recommends a minimum level of 1.4 for the Beta index and 0.75 for the CNR for walkable urban living spaces. The pedestrian accessibility index is the ratio of the length of the actual route to the geographical (bird's flight) shortest distance. If the index value is 1, accessibility for pedestrians is at the highest level; however, 1.5 is recommended as the upper limit (Litman. 2005). Southworth and Ben-Joseph (2013) stated that although grid-type connected street networks increase accessibility by providing shorter routes, they have relatively disadvantages in achieving livability, space quality, security, sociality, and public use. Less-connected networks (cul-de-sacs) are more advantageous in achieving the latter objectives. Since grid-like connected and dense networks offer many shortest path options, they reduce the total vehicle mile traveled (VMT), reduce energy consumption and carbon emissions, increase accessibility, and are more resilient networks as they provide alternative route opportunities in case of crises such as disasters (Sharifi, 2019). Zhang (2013) investigated the walkability and accessibility degrees of grid-planned and Radburn-like semi-connected networks for pedestrians, network density, alpha, and gamma indices and found that the former is more advantageous in terms of accessibility. Southworth and Ben-Joseph (1995) found that the annual average traffic accidents in grid-planned residential areas were 77.7 while only 10.2 in the networks, including cul-de-sac and three-legged street intersections. Taylor (2001) in lessconnected networks (Radburn or similar type street geometry), the average vehicle volume on the main roads is $75 \%$ higher than those of the grid plan. In addition, the total travel distance (vehicle mile traveled) is $43 \%$ more in less-connected networks than the grid ones.

Findings reveal that although the closeness, centrality, and accessibility indexes are higher for grid networks, safety and road efficiency are more disadvantageous since the number of intersections is relatively high. Street surface per unit area is more than less-connected ones. Zadeh and Rajabi (2013) measured network efficiency with centrality indicators like betweenness and closeness. They simulated traffic on hypothetical networks and found that grid network is less efficient. In contrast, less-connected networks are more efficient since street length per area and population are lower than grids. This result can be explained by the fact that the number of vehicles per unit distance road section is higher in the less connected networks of residential areas since the traffic density is relatively more minor at the peripheries of cities. Giacomin and Levinson (2015) measure network efficiency by the number of routes provided by the road network in a specified area, the number of streets per unit area, and the ratio of the route length to the geometric (bird flight) shortest distance. Háznagy and $\mathrm{Fi}$ (2016) conducted a field study and measured six different networks' travel time, average speed, efficiencies, and road utilization rates. Soltani and Allan (2005) calculated the walking permeability distance index (WPDI), a function of street width, pavement quality, and street connectivity.

One of the most important indicators used to compare road network geometric properties is traffic safety. Studies in this direction examine the relationships between the frequency and severity of accidents and the connectivity degrees of the street networks, intersection characteristics, and frequencies. In their comprehensive study, Marshall and Garrick (2010) compared the street networks of 24 medium-sized cities in California; cities were classified into two groups, safe and less safe, based on the rates of accidents per 100,000 populations. Accident with injury, serious injury, and death per total vehicle mile traveled (VMT) are other safety indicators. Two-factor analysis of variance (ANOVA) was applied in that study. Street networks are classified into four categories according to connectivity and link to node ratio (LNR) indices; low (between 01.1), common medium (between 1.1 and 1.25), medium-high (between 1.25-1.4), and high (higher than 1.4). Street networks are also classified according to intersection density which refers to the number of intersections per square mile; low dense (less than 81 intersections), low medium dense 
(81-143 intersections), medium-high dense (intersections between 144-224), and high dense (225 and more). Although different results were obtained in relatively safer (with fewer accidents per population) and less safe cities, no significant effects were obtained between the connectivity index (LNR) and the severity of the accident (fatality). Although the risk of fatal and severe injury accidents is relatively higher at four-leg intersections, statistically significant results could not be obtained since the number of crossings per unit area reduces the probability of an accident. Here, it is thought that the effect of vehicle speeds on the severity of the accident is high.

Marshall and Garrick (2011) examined 230.00 accidents in 473 cities in California between 1997 and 2007. They employed a negative binomial regression model to measure the relationship between street network properties and accident rates of 12 safest and least safe cities. Street networks were classified into 8 categories according to network densitycar. Accidents increase by $14.15 \%$ when the intersection per square mile decreases from 144 to 81 . When intersection density (per square mile) increases to 225 number of accidents decreases by $15.24 \%$ and $31.48 \%$ for 324 junctions per square mile. The findings can be explained by decreasing the number of vehicles per intersection. More vehicle crossings at fewer intersections can be described as a factor that increases the risk of accidents. Similar results were found for the rates of severe injuries and fatalities. Findings revealed that the accident rate increased as the link to node ratio (LNR) increased. When LNR increases from 1.25 to 1.4, the total number of accidents increases by $16.7 \%$ and the number of accidents with severe injuries increases by $13.9 \%$, and the number of fatal accidents increases by $39.3 \%$. In that study, there was a significant correlation between the total vehicle mile traveled (VMT) and the total number of casualties, the number of severe accidents. Still, no significant results were obtained between fatal accidents.

\section{Method}

In the literature, various forms of regression models are employed to measure the effects of variables on accident occurrence. In addition to socio-economic factors, physical factors like street network properties, intersection type, traffic control measures may contribute to accident occurrence. This study employs a series of regression models to understand how street networks influence accident rates. The linear form of the multiple regression equation is as follows:

$A=B_{0}+B_{1} X_{1}+B_{2} X_{2}+\ldots B_{n} X_{n} e$

Where;
A: Annual average number of accidents (dependent variable)
$\boldsymbol{X}_{i}$ : Independent variable
Bi: Predictors
e: error

When the equation is specified for his study the regression model takes the following form:

$A=f(P D . S L . S D)$

Where;
A: Annual average number of accidents (dependent variable)
PD: Population density
SL: Streel length
$S D$ : Street density.

Demographic and economic factors have a significant role in accident occurrence. In this study the roles of socio economic and physical attributes are investigated independently. By the way in the statistical analysis the most effective physical factors can be distinguished among all. Equation 1 was employed to explore the relationship between neighborhood figures and accident occurrence be operationalized in the following form

$\mathrm{A}=\beta_{0}+\beta_{1} \mathrm{P}+\beta_{2} \mathrm{E}+\beta_{3} \mathrm{C}+e$

Where;

A: Number of Accidents 

P: Population
E: Employment
C: Number of Cars
$\boldsymbol{\beta}_{0}$ : the intercept
$\beta_{1}, \beta_{2}, \beta_{3}$ : regression coefficients
$\boldsymbol{e}$ : the error term

In the second stage of regression analysis, street network properties by neighborhood are identified. Thus Model 2 be operationalized in the following form

$\mathrm{A}=\beta_{0}+\beta_{1} \mathrm{PD}+\beta_{2} \mathrm{SL}+\beta_{3} \mathrm{NL}+\beta_{4} \mathrm{SD}+\beta_{5} \mathrm{SLP}+\beta_{6} \mathrm{NI}+\beta_{7} \mathrm{LNR}+\beta_{8} \mathrm{ALL}+e$

Where;
A: Number of Accidents
PD: Population density
SL: Street length
NL: Number of links
SD: Street density
SLP: Street length per capita
NI: Number of Intersections
LNR: Link to node ratio
ALL: Average link length
$\beta_{0}$ : the intercept
$\boldsymbol{\beta}_{1} \ldots \boldsymbol{\beta}_{\mathbf{8}}$ : regression coefficients
$\boldsymbol{e}$ : the error term

The city's neighborhood is classified/ranked according to traffic safety indicators (accident per 1000 population). Then the street patterns of the most and least safe neighborhoods are elaborated according to the following indicators:

- $\quad$ Street density (SD)= Street Length (meters)/neighborhood area (hectares),

- Population density (PD)= Population/neighborhood area (hectares),

- $\quad$ Street length per capita (SLP)=Street Length (meters)/population,

- $\quad$ The share of street surface area (SSA)=Street surface area (sq.m), neighborhood area (sq.m),

- $\quad$ Street surface per capita (SSC)= Street surface area (sq.m)/population,

- Intersection density (ID)=Number of intersections/ neighborhood area (hectares),

- $\quad$ Share of three-legged junctions (3LIR)= Three-legged intersections/total number of intersections,

- $\quad$ Share of three-legged junctions (4LIR)= Four-legged intersections/total number of intersections,

- Link to node ratio (LNR)=number of local street links/number of local nodes,

Traffic safety indicators that are used to compare the corresponding neighborhoods are as follows:

- Accident per 1000 Population (APP)= 1000*Number of Accidents/ Population,

- Accident per Kilometer Street Length (APS)= Number of Accidents/Street Length (kilometers),

- $\quad$ Accident per Intersection (API)= Number of Accidents/ Number of Intersections.

Although Connected Node Ratio (CNR) is mentioned in the literature as a significant indicator, the dead-end street (cul-de-sac) design is not common in Mersin city.

Accident data are obtained from the Ministry of Interior. General Directorate of Security. Population figures are obtained from the Turkish Statistical Institute (TUIK), demographic indicators by neighborhood database (https://biruni.tuik.gov.tr). Street network was obtained from Open Street (https://www.openstreetmap.org) and Google Earth. 


\section{Empirical Findings}

In the city, 8131 accidents occurred in Mersin city from 2015 to 2017 . While $30.2 \%$ (2453) of accidents occurred at local streets, the majority (69.8) of accidents occurred at major arterials (Figure 1).

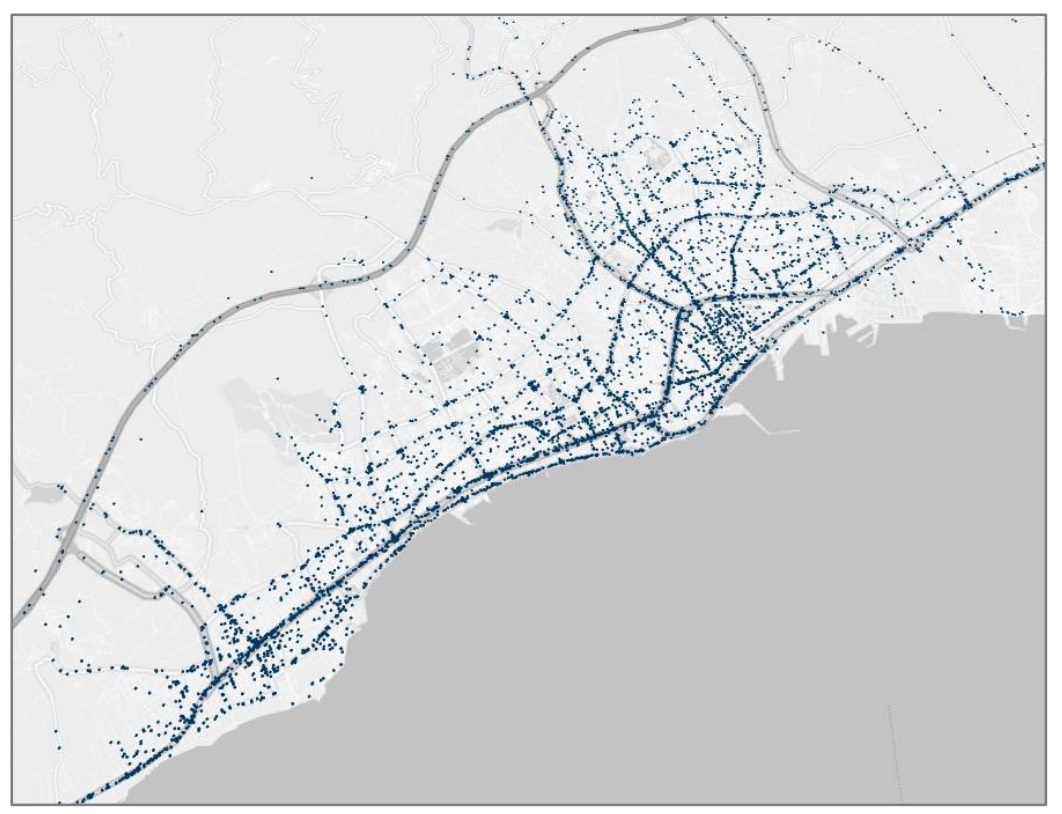

Figure 1 Spatial location accidents Source: from Ministry of Interior. General Directorate of Security. The map was prepared in MS Excel 2016.

Accident occurrence rates and densities are higher in the central business district and industrial zones, located in the eastern part of the city. Because at those parts of the city, population densities are relatively low, and non-residential urban activities (retail, industry, manufacturing, warehousing, business, and commercial) generate higher rates of traffic (Figure 2).

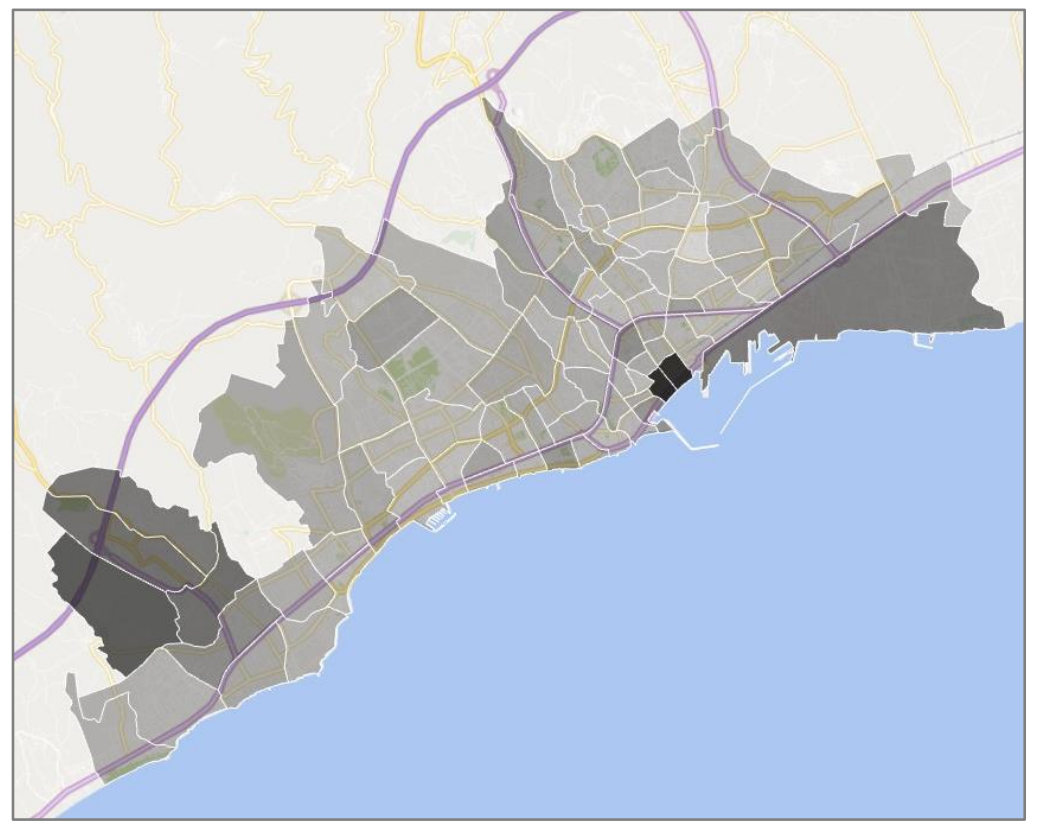

Figure 2 Accident per population by neighborhood (accidents at local streets only) Source: from Ministry of Interior. General Directorate of Security. Prepared in MS Excel 2016.

Regression analysis results showed that population, employment, and car (automobile) per neighborhood have a significant role in accident occurrence at the local street (Table 1). Results 
show that 1000 population is responsible for 0.97 accidents, while additional 1000 employment causes 2.84 accidents and additional 1000 cars generate 5.57 accidents $\left(R^{2}=0.664\right)$.

Table 1 Model 1 Regression Results (Model summary, ANOVA and Coefficients)

\begin{tabular}{|c|c|c|c|c|c|c|c|c|}
\hline \multicolumn{9}{|c|}{ Model Summary } \\
\hline Model & $\mathrm{R}$ & R Square & \multicolumn{3}{|c|}{ Adjusted R Square } & \multicolumn{3}{|c|}{ Std. Error of the Estimate } \\
\hline 1 & $.815^{\mathrm{a}}$ & .664 & \multicolumn{3}{|c|}{.652} & \multicolumn{3}{|r|}{11.375} \\
\hline \multicolumn{9}{|c|}{ a. Predictors: (Constant). \# of Cars (2016). Employment (2016). Pop. (2016) } \\
\hline \multicolumn{9}{|c|}{ ANOVA $^{a}$} \\
\hline \multicolumn{2}{|l|}{ Model } & \multicolumn{2}{|c|}{ Sum of Squares } & \multicolumn{2}{|l|}{ df } & Mean Square & $\mathrm{F}$ & Sig. \\
\hline \multirow[t]{3}{*}{1} & Regression & \multicolumn{2}{|r|}{20754.970} & \multicolumn{2}{|r|}{3} & 6918.323 & 53.5 & $.000^{\mathrm{b}}$ \\
\hline & Residual & \multicolumn{2}{|r|}{10480.606} & \multicolumn{2}{|c|}{81} & 129.390 & & \\
\hline & Total & \multicolumn{2}{|c|}{31235.306} & \multicolumn{2}{|c|}{84} & & & \\
\hline \multicolumn{9}{|c|}{ a. Dependent Variable: \# of Accidents } \\
\hline \multicolumn{9}{|c|}{ b. Predictors: (Constant). \# of Cars (2016). Employment (2016). Pop. (2016) } \\
\hline \multicolumn{9}{|c|}{ Coefficients $^{\mathrm{a}}$} \\
\hline \multirow[t]{2}{*}{ Model } & & & \multicolumn{2}{|c|}{$\begin{array}{l}\text { Unstandardized } \\
\text { Coefficients }\end{array}$} & \multirow{2}{*}{\multicolumn{2}{|c|}{$\begin{array}{c}\text { Standardized } \\
\text { Coefficients }\end{array}$}} & $\mathrm{t}$ & Sig. \\
\hline & & & B & Std. Error & & & & \\
\hline \multirow[t]{4}{*}{1} & \multicolumn{2}{|l|}{ (Constant) } & 2.523 & 2.640 & & & .956 & .342 \\
\hline & \multicolumn{2}{|c|}{1000 Pop. (2016) } & 0.97 & .276 & & .320 & 3.507 & .001 \\
\hline & \multicolumn{2}{|c|}{1000 Employment } & 2.84 & .592 & & .315 & 4.767 & .000 \\
\hline & \multirow{2}{*}{\multicolumn{2}{|c|}{\begin{tabular}{|l|l}
1000 Cars (2016) & \\
\end{tabular}}} & 5.57 & 1.229 & & .420 & 4.622 & .000 \\
\hline \multicolumn{7}{|c|}{ a. Dependent Variable: Annul Average \# of Accidents } & & \\
\hline
\end{tabular}

Research findings proved that car (automobile) ownership rate positively contributes to accident occurrence. In the city, higher rates are observed at the northwest and west parts of the city, while neighborhoods at the east and northeast parts accommodate the lowest rates (Figure 3 ).

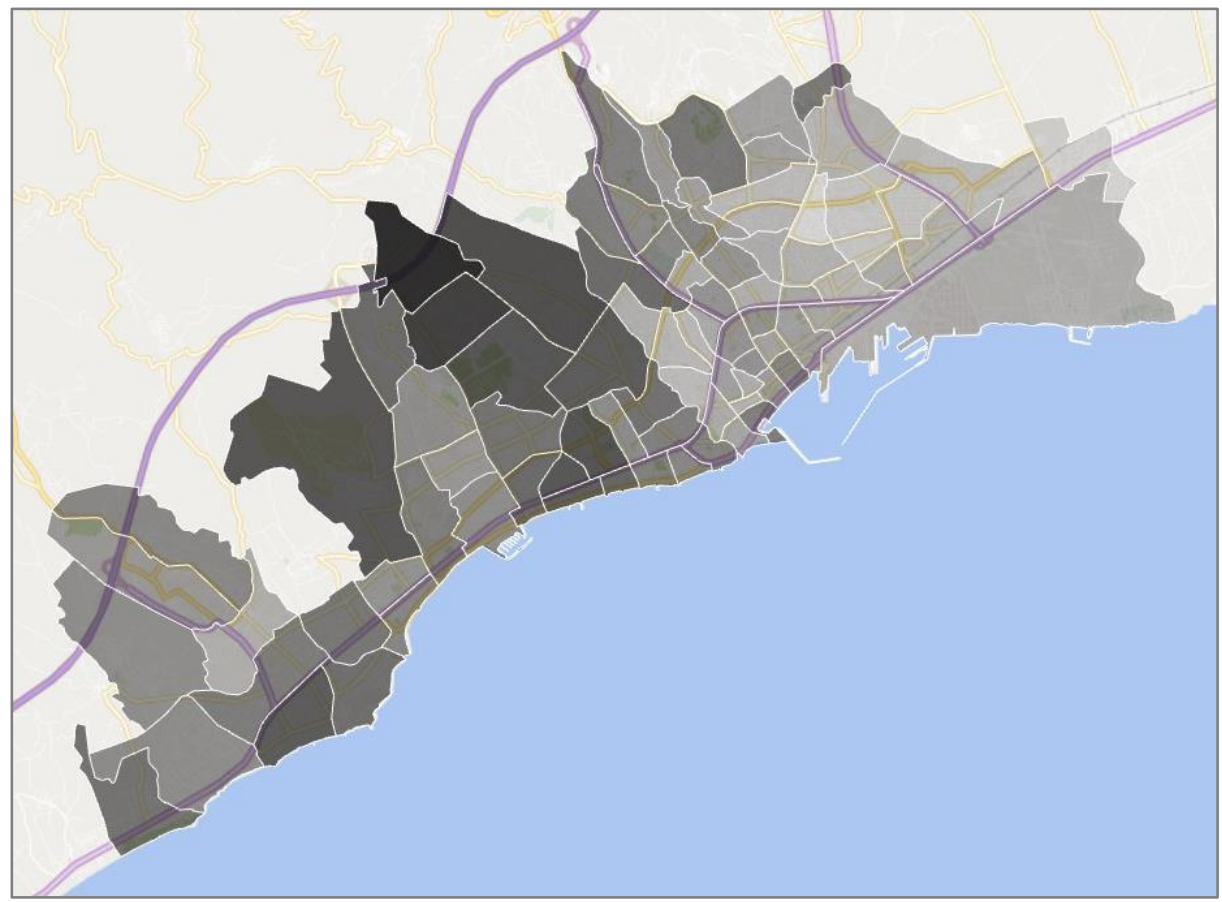

Figure 3 Automobile ownership rates by neighborhood Source: Adapted from Mersin Transport Master Plan (Boğaziçi Proje. 2015), Prepared in MS Excel 2016.

Model 2 results showed that population density, street length per capita (meters), and number of intersections significantly affect accident occurrence. Number of intersections increases accident frequencies while street length per capita reduces. In contrast, the number of links, street density, link to node ratio, and average link length have no significant effect on accident occurrence (Table 2). 
Table 2 Model 2 Regression Results (Stage 2, Model summary, ANOVA and Coefficients)

\begin{tabular}{|c|c|c|c|c|c|c|c|c|c|}
\hline \multicolumn{10}{|c|}{ Model Summary } \\
\hline \multicolumn{2}{|c|}{ Model } & $\mathrm{R}$ & R Square & \multicolumn{2}{|c|}{ Adjusted R Square } & \multicolumn{4}{|c|}{ Std. Error of the Estimate } \\
\hline \multicolumn{2}{|c|}{1} & ,609 & ,371 & & ,323 & \multicolumn{4}{|c|}{15,89296} \\
\hline \multicolumn{10}{|c|}{$\begin{array}{l}\text { a. Predictors: (Constant), average link length (m), \# of intersections, street length per capita (m/p), } \\
\text { link/node, street density, \# of Links }\end{array}$} \\
\hline \multicolumn{10}{|c|}{ ANOVA $^{\mathrm{a}}$} \\
\hline \multicolumn{3}{|c|}{ Model } & $\begin{array}{l}\text { Sum of } \\
\text { Squares }\end{array}$ & df & \multicolumn{2}{|c|}{ Mean Square } & $\mathrm{F}$ & \multicolumn{2}{|l|}{ Sig. } \\
\hline \multirow{3}{*}{1} & \multicolumn{2}{|c|}{ Regression } & 11628,577 & 6 & \multicolumn{2}{|c|}{1938,096} & 7,673 & \multicolumn{2}{|r|}{, $000^{\mathrm{b}}$} \\
\hline & \multicolumn{2}{|c|}{ Residual } & 19701,729 & 78 & \multirow{2}{*}{\multicolumn{2}{|c|}{252,586}} & & & \\
\hline & \multicolumn{2}{|c|}{ Total } & 31330,306 & 84 & & & & & \\
\hline \multicolumn{10}{|c|}{ a. Dependent Variable: Annual Average Accidents (local streets) } \\
\hline \multicolumn{10}{|c|}{$\begin{array}{l}\text { b. Predictors: (Constant), average link length (m), \# of intersections, street length per capita }(\mathrm{m} / \mathrm{p}) \text {, } \\
\text { link/node, street density, \# of Links }\end{array}$} \\
\hline \multicolumn{10}{|c|}{ Coefficients ${ }^{\mathrm{a}}$} \\
\hline \multirow{2}{*}{\multicolumn{4}{|c|}{ Model }} & \multicolumn{2}{|c|}{$\begin{array}{l}\text { Unstandardized } \\
\text { Coefficients }\end{array}$} & & $\begin{array}{l}\text { רdardized } \\
\text { efficients }\end{array}$ & \multirow[t]{2}{*}{$\mathrm{t}$} & \multirow[t]{2}{*}{ Sig. } \\
\hline & & & & $\mathrm{B}$ & Std. Error & & Beta & & \\
\hline \multirow{7}{*}{1} & \multicolumn{3}{|c|}{ (Constant) } & $-37,670$ & 29,627 & & & $-1,271$ & ,207 \\
\hline & \multicolumn{3}{|c|}{ \# of Links } &,- 340 & ,252 & & $-1,158$ & $-1,349$ & 181 \\
\hline & \multicolumn{3}{|c|}{ street density } & 013 & ,302 & & ,005 &, 042 & 966 \\
\hline & \multicolumn{3}{|c|}{ street length per capita } & $-3,197$ & 1,180 & &,- 271 & $-2,709$ & ,008* \\
\hline & \multicolumn{3}{|c|}{$\#$ of intersections } & 691 & ,345 & & 1,742 & 2,001 & ,049* \\
\hline & \multicolumn{3}{|c|}{ link/node } & 32,335 & 19,078 & & ,257 & 1,695 & ,094 \\
\hline & \multicolumn{3}{|c|}{ average link length $(\mathrm{m})$} & ,066 & , 040 & & ,175 & 1,649 & 103 \\
\hline
\end{tabular}

It is observed that some variables have no significant effect on accident occurrence. Therefore, essential variables are selected in the third stage, $d$ and a new form of the equation (Model 3 ) is identified, the model can be operationalized in the following form

$\mathbf{A}=\beta_{0}+\beta_{1} \mathrm{SL}+\beta_{2} \mathrm{NI}+e$

Where;

A: Number of Accidents,

SL: Street length,

NI: Number of intersections,

$\beta_{0}$ : the intercept,

$\beta_{1}, \beta_{2}$ : regression coefficients,

$\boldsymbol{e}$ : the error term.

At the final stage, insignificant variables of Stage 2 are eliminated, and the model results of Stage 3 are presented in Table 3.

Table 3 Stage 3 Regression Results (Model summary. ANOVA and Coefficients)

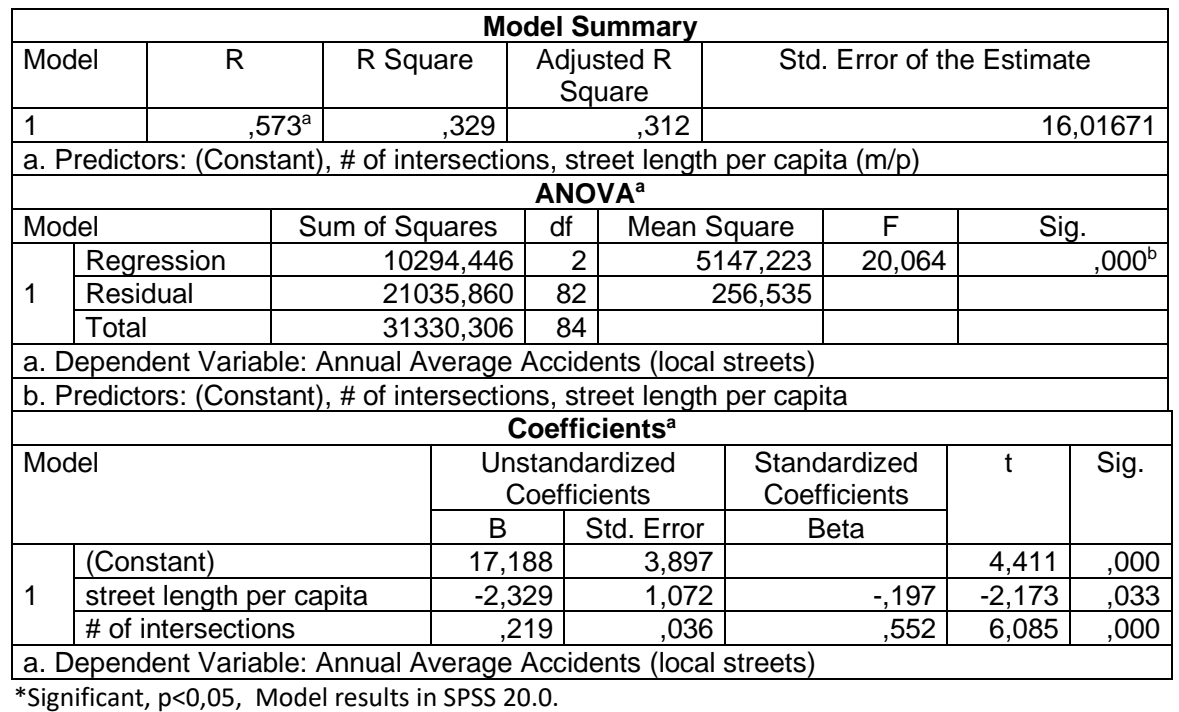


Empirical results showed that street length per capita (SPC) is positively correlated with population density (PD), but the former one is an inverse exponential multiplier of the latter one (Figure 4A). In addition, positive correlation was found between street density (SD) and population density (Figure 4b).

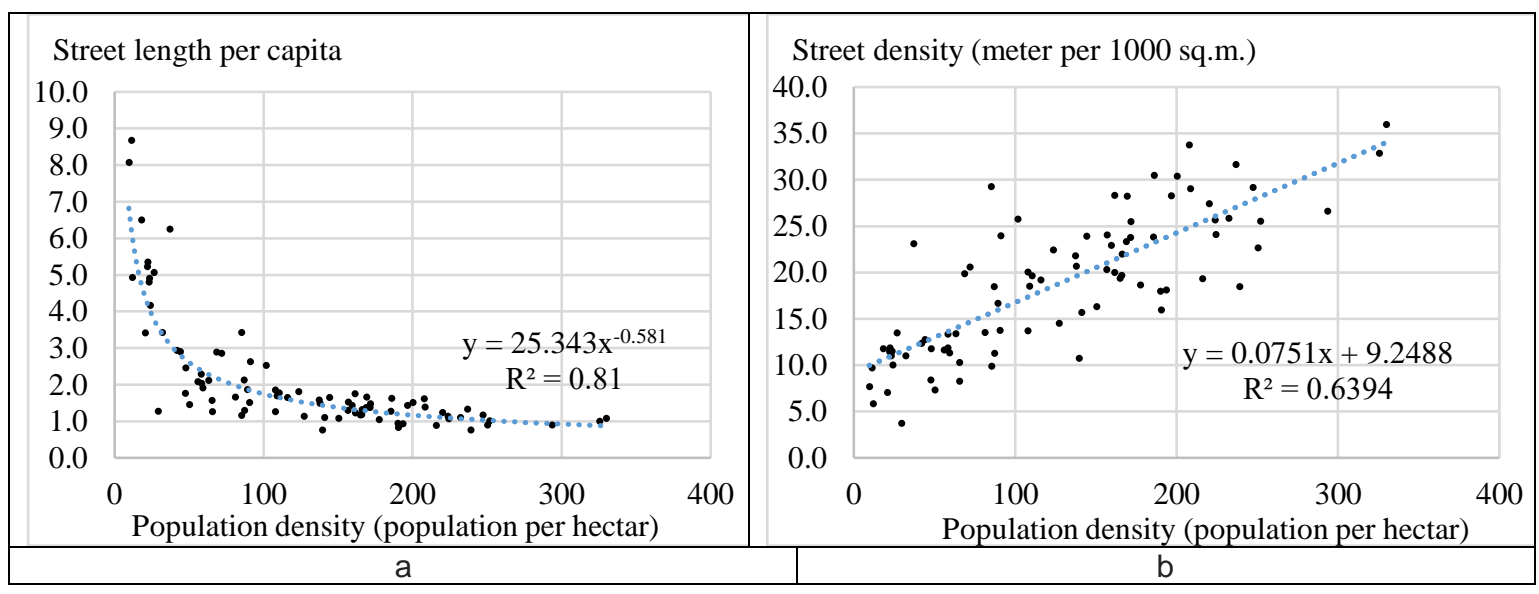

Figure 4 Correlations among street length per capita. street density and population density

Intersection type can be an influencing factor of accident occurrence and the severity of crashes. A disaggregate model is employed at the neighborhood scale to assess the role of intersection type, but significant results are not obtained. Therefore, an aggregate analysis is conducted, and it is found that $73 \%(1791 / 2554)$ of crashes occurred at intersections while $27 \%(663 / 2554)$ of them were observed at the roadside (street sections). However, the accuracy of coordinates is limited at street scale. In addition, further studies are necessary to investigate the severity of the crashes and the roles of vehicle type, traffic control measures, and driver profile. In this respect, Binomial Logistics Regression may provide more reliable results. The following section street network patterns of the selected neighborhoods where traffic safety indicators are highest and lowest.

\section{Spatial Analysis}

Empirical analysis revealed notable differences among neighborhoods in terms of traffic safety. Accident rates (accident per 1000 population) are dramatically high in the city center and around industrial zones. These figures are not surprising since the population is less while non-residential activities and traffic volumes are in those parts of the city. In the following amount, street networks of residential neighborhoods are compared to minimize the influence of land use and employment in the safety of the neighborhoods. Those located around the central business district and nearby industrial zones are excluded. Four residential neighborhoods with higher accident rates than the city average are Eski Mezitli, H.O.Merzeci, Mezitli-Merkez, and Aydınlıkevler (Table 4).

Table 4 Spatial Figures of Top 20 Neighborhoods (With Highest Rates of Accidents)

\begin{tabular}{|c|c|c|c|c|c|c|c|c|c|c|c|c|}
\hline 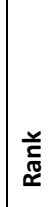 & 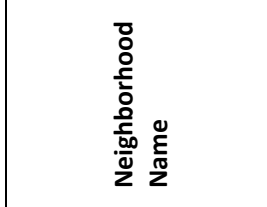 & $\begin{array}{l}\overline{0} \\
\stackrel{0}{0} \\
\dot{0} \\
\dot{0}\end{array}$ & 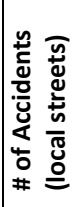 & 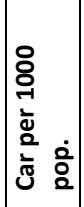 & 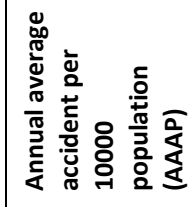 & 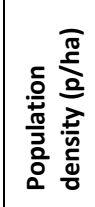 & 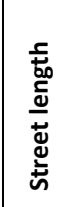 & 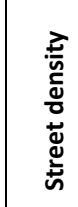 & 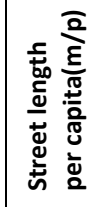 & 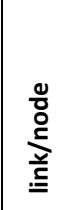 & 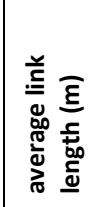 & 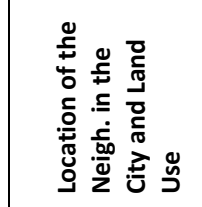 \\
\hline 1 & ÇANKAYA (MERKEZ) & 939 & 13 & 100 & 46.1 & 31 & 4.0 & 13.5 & 4.3 & 1.48 & 118 & City Center \\
\hline 2 & CAMI ŞERIF & 1737 & 22 & 136 & 42.2 & 47 & 8.6 & 23.2 & 4.9 & 1.73 & 120 & City Center \\
\hline 3 & ESKI MEZITLI & 1754 & 19 & 147 & 36.1 & 18 & 11.4 & 11.8 & 6.5 & 1.32 & 212 & Residential \\
\hline 4 & KARADUVAR & 9913 & 79 & 73 & 26.6 & 10 & 79.8 & 7.7 & 8.0 & 1.22 & 191 & Industrial Zone \\
\hline 5 & MAHMUDIYE & 3852 & 26 & 144 & 22.5 & 168 & 6.5 & 28.3 & 1.7 & 1.46 & 120 & City Center \\
\hline 6 & IHSANIYE & 5190 & 32 & 140 & 20.6 & 110 & 9.2 & 19.7 & 1.8 & 1.53 & 128 & Near CBD \\
\hline 7 & ÜÇOCAK & 4230 & 26 & 91 & 20.5 & 58 & 9.7 & 13.4 & 2.3 & 1.41 & 187 & Near CBD \\
\hline 8 & MESUDIYE & 8585 & 49 & 104 & 19.0 & 329 & 8.6 & 32.9 & 1.0 & 1.42 & 77 & City Center \\
\hline
\end{tabular}




\begin{tabular}{|l|l|l|l|l|l|l|l|l|l|l|l|l|}
9 & KÜLTÜR & 3337 & 18 & 176 & 18.0 & 92 & 4.1 & 11.3 & 1.2 & 1.48 & 90 & City Center \\
\hline 10 & YENi (MERKEZ) & 15830 & 83 & 110 & 17.5 & 190 & 13.3 & 16.0 & 0.8 & 1.42 & 135 & Near CBD \\
\hline 11 & KIREMiTHANE & 3146 & 16 & 65 & 17.0 & 238 & 3.4 & 25.9 & 1.1 & 1.38 & 118 & Near CBD \\
\hline 12 & HAMIDIYE & 4900 & 24 & 93 & 16.3 & 143 & 3.7 & 10.8 & 0.8 & 1.41 & 90 & City Center \\
\hline 17 & H.O.MERZECI & 5768 & 28 & 210 & 16.2 & 49 & 13.6 & 11.7 & 2.4 & 1.35 & 121 & Residential \\
\hline 13 & BAHÇE & 3989 & 19 & 78 & 15.9 & 226 & 4.3 & 24.1 & 1.1 & 1.46 & 104 & Near CBD \\
\hline 14 & NUSRATIYE & 10217 & 48 & 139 & 15.7 & 296 & 9.2 & 26.6 & 0.9 & 1.67 & 112 & Near CBD \\
\hline 15 & BARIŞ & 5883 & 27 & 112 & 15.3 & 172 & 8.7 & 25.5 & 1.5 & 1.45 & 104 & Near CBD \\
\hline 16 & ÖZGÜRLÜK & 6565 & 29 & 64 & 14.7 & 43 & 19.0 & 12.4 & 2.9 & 1.30 & 200 & Industrial Zone \\
\hline 18 & MEZITLi-MERKEZ & 22776 & 92 & 208 & 13.5 & 99 & 31.8 & 13.7 & 1.4 & 1.38 & 147 & Residential \\
\hline 19 & AYDINLIKEVLER & 10543 & 41 & 283 & 13.0 & 223 & 12.2 & 25.7 & 1.2 & 1.42 & 103 & Residential \\
\hline 20 & FUATMOREL & 8644 & 32 & 324 & 12.3 & 19 & 32.1 & 7.1 & 3.7 & 1.37 & 206 & Residential \\
\hline
\end{tabular}

Eski Mezitli is the first ranking residential neighborhood where the average annual accident per 1000 population was 36.1 . The neighborhood is recently developed around a village. Therefore, the street network does not meet standards and increases vehicle trips (Figure 5). The high rate of accidents, in this case, can also be explained by the increased number of vehicles and limited number of links. In addition, intersections are not properly designed yet, which is a contributing factor in accident occurrence.
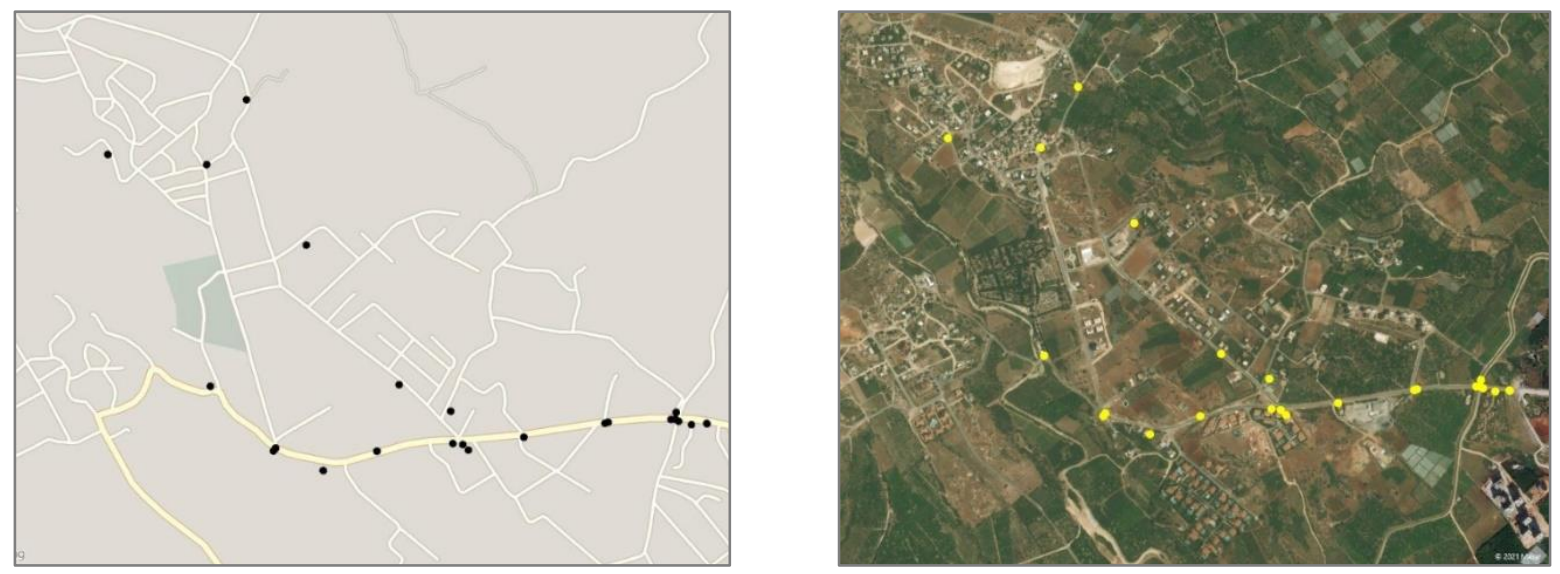

Figure 5 Street Network and Location of Accidents in Eski-Mezitli Neighborhood

Hüseyin Okan Merzeci is also a recently developed residential neighborhood. The street network is in an irregular form (Figure 6) and serves to increasing vehicle volumes generated by residents of newly built high-rise apartments. Improper design of street geometry and intersections contributes to high rates of accidents ( 16.2 average annual accidents per 1000 population).
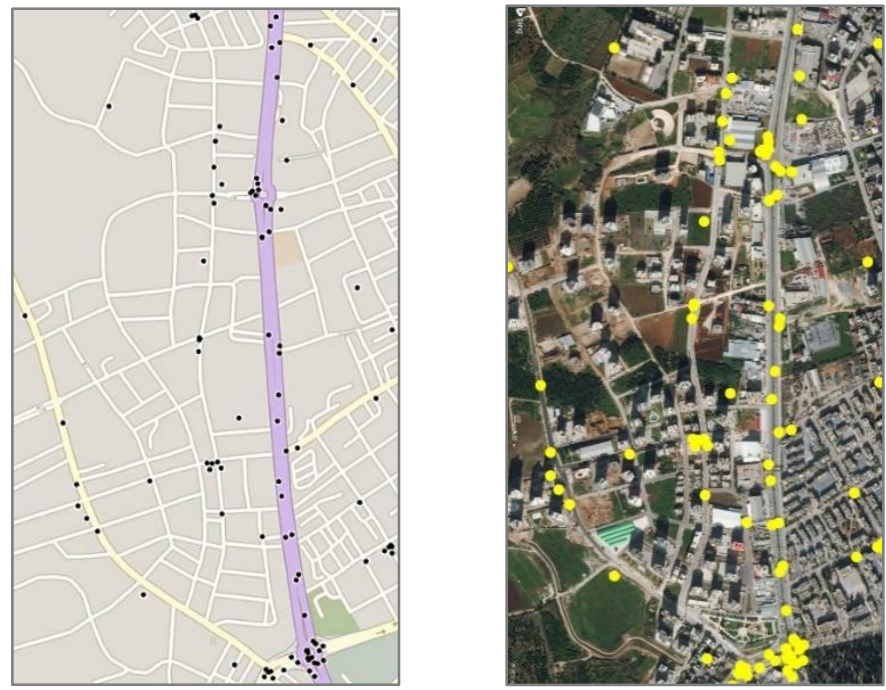

Figure 6 Street Network and Location of Accidents in H.O.Merzeci Neighborhood 
Mezitli Merkez is one of the most populated $(22,776)$ neighborhoods and accommodates middle and upper-middle-income dwellers. Car ownership rate is over city average and one of the most effective contributing factors in the increasing number of accidents. Even though the residential and some retail centers are outcomes of the planned development, the street network and intersections are not properly designed (Figure 7); hence some streets accommodate a pretty high number of accidents (13.5 per 1000 population).
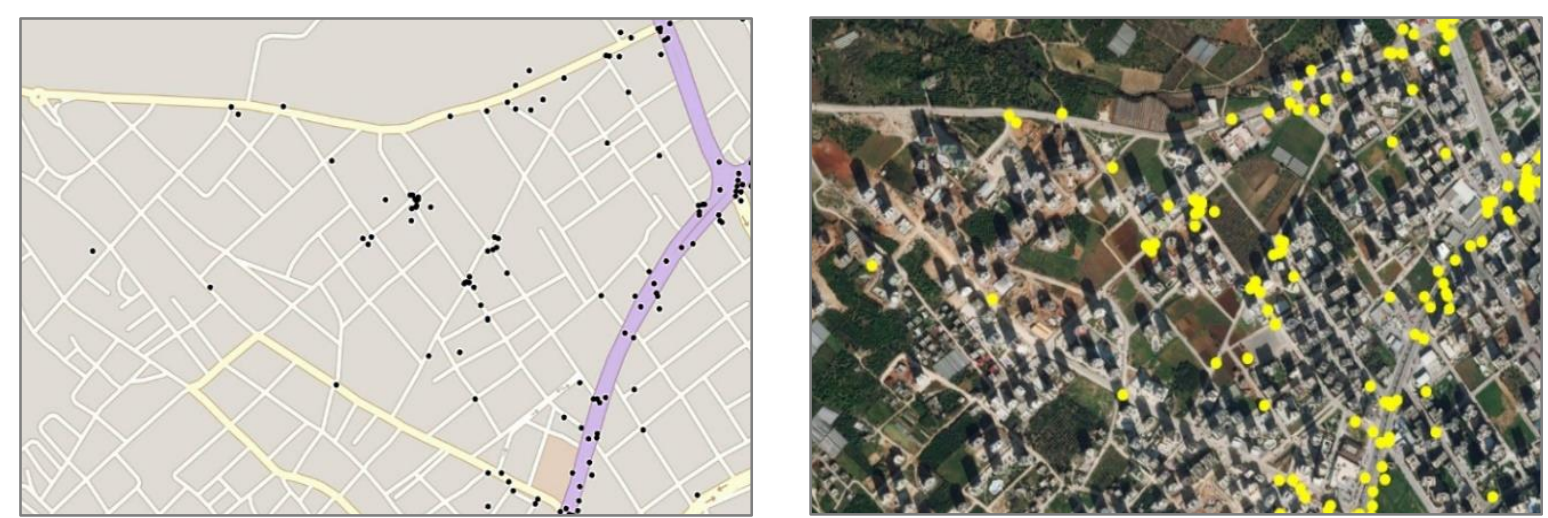

Figure 7 Street Network and Location of Accidents in Mezitli-Merkez Neighborhood

Residential development in the Aydınlıkevler neighborhood dated back to 1970's in an unauthorized way. After 1980's areas has experienced planned growth, and local plans promoted high-rise apartments. Street sections and intersections were not designed to accommodate vehicles (Figure 8), therefore increasing the rate of car ownership, increasing the share of nonresidential uses, and street network are responsible for low traffic safety rates.
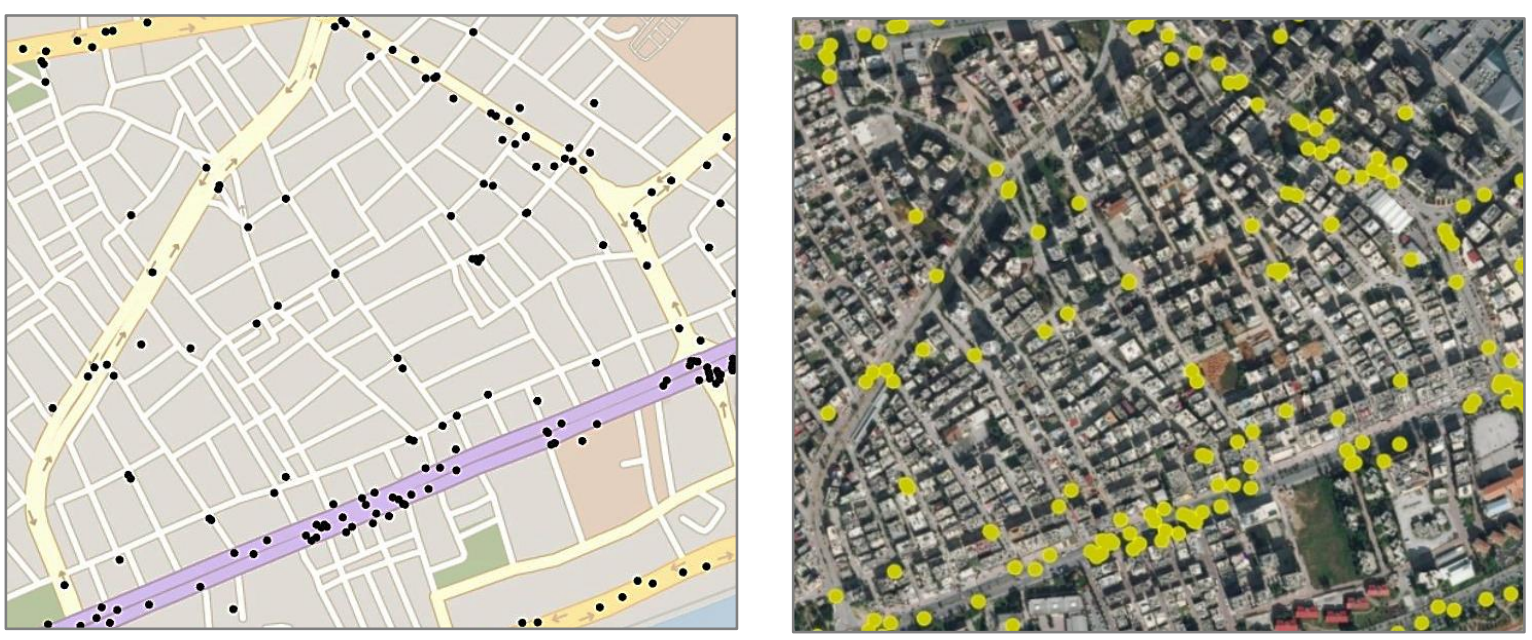

Figure 8 Street Network and Location of Accidents in Aydınlıkevler Neighborhood

Four residential neighborhoods where accident rates are lower than city average are Çağdaşkent, Kocavilayet, Piri Reis and Güneş (Table 5).

Table 5 Spatial Figures of Safest 20 Neighborhoods (With Lowest Rates of Accidents)

\begin{tabular}{|c|c|c|c|c|c|c|c|c|c|c|c|c|}
\hline 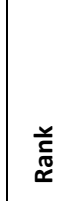 & 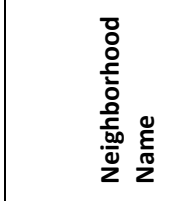 & 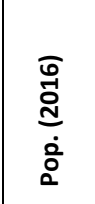 & 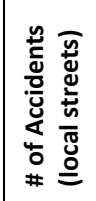 & 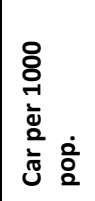 & 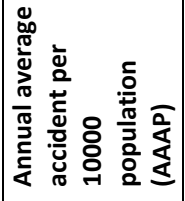 & 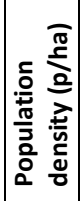 & 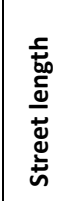 & 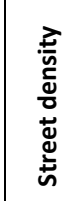 & 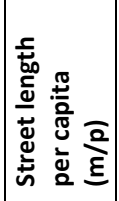 & 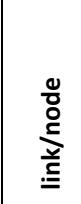 & 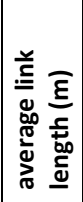 & 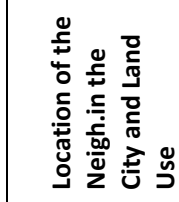 \\
\hline 66 & ÇAVUŞLU & 6203 & 14 & 127 & 7.5 & 68 & 18.0 & 19.9 & 2.9 & 1.73 & 117 & Non-Planned \\
\hline 67 & ZEKI AYAN & 6235 & 14 & 86 & 7.5 & 132 & 9.8 & 20.7 & 1.6 & 1.90 & 125 & Residential \\
\hline 68 & TOZKOPARAN & 14791 & 33 & 140 & 7.4 & 207 & 20.8 & 29.1 & 1.4 & 1.65 & 138 & Residential \\
\hline 69 & GÜVENEVLER & 19491 & 43 & 283 & 7.4 & 171 & 26.6 & 23.4 & 1.4 & 1.66 & 163 & Residential \\
\hline
\end{tabular}




\begin{tabular}{|l|l|l|l|l|l|l|l|l|l|l|l|l|}
70 & BARBAROS & 12790 & 28 & 235 & 7.3 & 159 & 18.4 & 22.9 & 1.4 & 1.55 & 172 & Residential \\
\hline 71 & CAĞDAŞKENT & 17517 & 37 & 209 & 7.0 & 79 & 30.1 & 13.6 & 1.7 & 1.67 & 192 & Residential \\
\hline 72 & EĞRiÇAM & 17317 & 36 & 152 & 6.9 & 117 & 28.5 & 19.2 & 1.6 & 1.71 & 156 & Non-Planned \\
\hline 73 & MUSTAFA KEMAL & 2954 & 6 & 76 & 6.8 & 46 & 7.6 & 11.8 & 2.6 & 1.35 & 181 & Non-Planned \\
\hline 74 & SELÇUKLAR & 12087 & 24 & 82 & 6.6 & 201 & 18.3 & 30.4 & 1.5 & 1.50 & 142 & Non-Planned \\
\hline 75 & TOROSLAR & 9201 & 18 & 112 & 6.5 & 142 & 15.5 & 23.9 & 1.7 & 1.52 & 147 & Non-Planned \\
\hline 76 & TURUNÇLU & 7855 & 14 & 55 & 5.9 & 216 & 12.3 & 33.8 & 1.6 & 1.45 & 137 & Non-Planned \\
\hline 77 & KOCAVILAYET & 2485 & 4 & 473 & 5.4 & 10 & 15.3 & 5.9 & 6.2 & 1.29 & 243 & Residential \\
\hline 78 & PIRIREIS & 9442 & 13 & 171 & 4.6 & 195 & 8.8 & 18.2 & 0.9 & 1.86 & 162 & Residentialoffice \\
\hline 79 & MÜFIDE İLHAN & 4880 & 5 & 81 & 3.4 & 93 & 12.6 & 24.0 & 2.6 & 1.55 & 166 & Non-Planned \\
\hline 80 & KURDALi & 16077 & 15 & 62 & 3.1 & 237 & 21.5 & 31.7 & 1.3 & 1.52 & 116 & Non-Planned \\
\hline 81 & ÇAY & 13109 & 12 & 25 & 3.1 & 67 & 20.3 & 10.3 & 1.5 & 1.37 & 97 & Non-Planned \\
\hline 82 & SEVKETSÜMER & 24204 & 21 & 28 & 2.9 & 161 & 30.2 & 20.1 & 1.2 & 1.48 & 162 & Non-Planned \\
\hline 83 & GÜNDOĞDU & 16575 & 14 & 68 & 2.8 & 191 & 26.5 & 30.5 & 1.6 & 1.49 & 163 & Non-Planned \\
\hline 84 & MEVLANA & 16237 & 13 & 52 & 2.7 & 154 & 25.4 & 24.1 & 1.6 & 1.46 & 154 & Non-Planned \\
\hline 85 & GÜNES & 22783 & 16 & 25 & 2.3 & 336 & 24.4 & 36.0 & 1.1 & 1.46 & 99 & Non-Planned \\
\hline
\end{tabular}

Some of the neighborhoods have similarities in terms of land use, physical development, housing types, and street patterns, and are advantageous in terms of traffic safety since car ownership rates are quite low (less than 100 vehicles per 1000 population). However, street networks are shaped in an irregular rectangular grid form and provide limited maneuver capability for vehicles, unlike others.

Çağdaşkent is one of the suburban types of planned development neighborhoods at the northeastern periphery of the city. Çağdaşkent is one of the identical examples of planned residential neighborhoods in the city since 1980's (Figure 9). Although car ownership rate (209 cars per 1000 population) was over the city average (150/1000), and street length per capita (1.7 meters) is below the city average, and accident rates are quite low (average annual accident rate per 1000 thousand population was 7.0). Singe family houses in a detached form (low-density development), clusters and cul-de-sacs, and loop-type street patterns seem to contribute to traffic safety. The street network of the southern part of the neighborhood is in a grid form, and the majority of the accidents occurred at that part. The street sections and intersections are appropriately designed to accommodate vehicles and reduce accident rates.
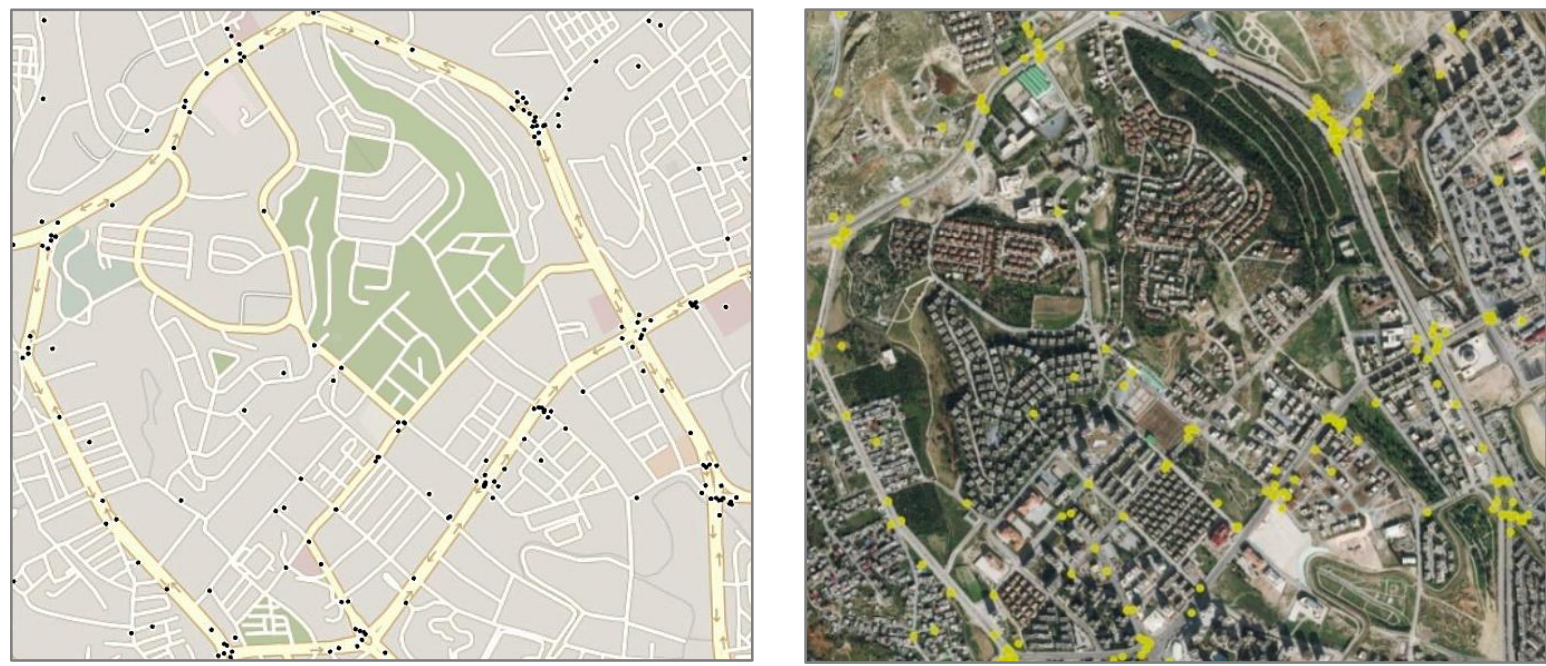

Figure 9 Street Network and Location of Accidents in Çağdaşkent Neighborhood 
Kocavilayet is a village located at the northwestern periphery of the city. Housing development in the last decades is segregated into two forms; hoses of villages and detached low rise singe family houses of highest income dwellers (Figure 10). The recently developed houses are designed in clustered forms which is the typical form of residential development since 1990's. Even though the neighborhood has the highest rate of car ownership (473/1000) accident rate is quite low (5.4). Street length per capita is 6.9 is much over city average (1.7) since population density is still low. Residential development is ongoing and accident rates may increase due to increasing population and number of cars, however street network is in an irregular form and not properly designed to accommodate higher volumes of vehicles.
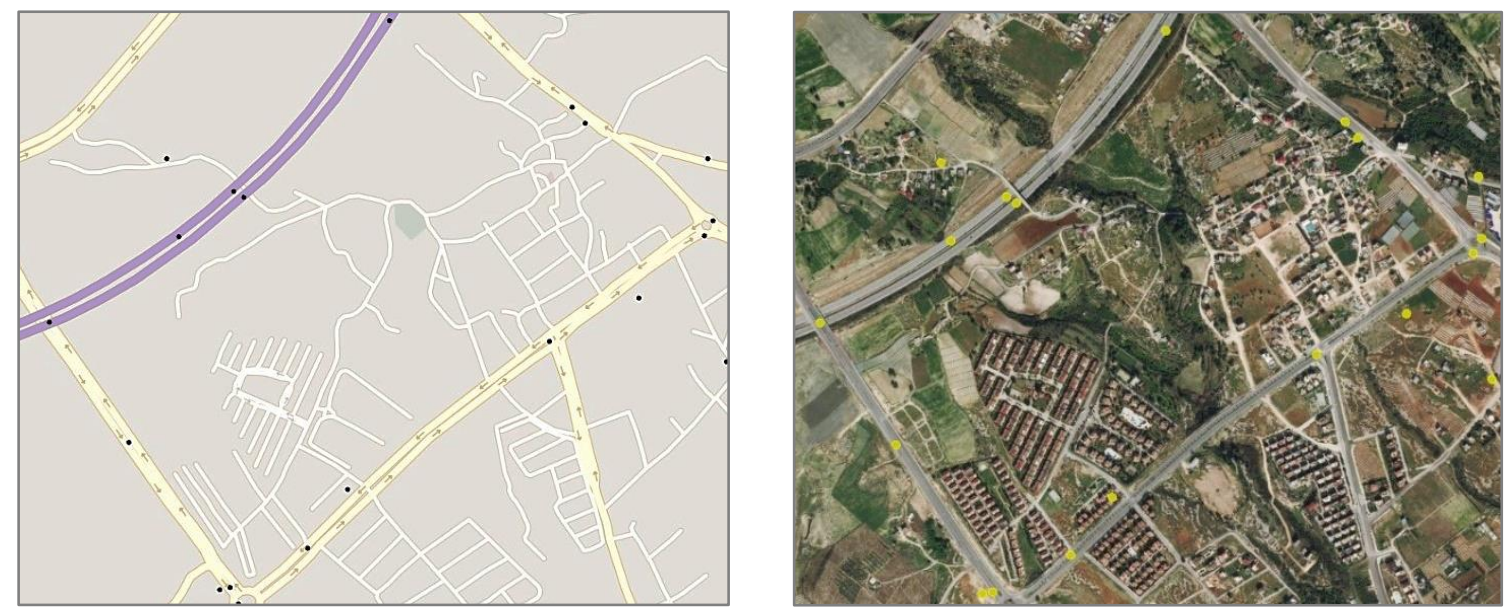

Figure 10 Street Network and Location of Accidents in Kocavilayet Neighborhood

The municipality adopted traffic safety measures like designing dead-end streets on a grid network. These measures effectively reduced accident rates in the Pirireis neighborhood, which is located at the western periphery of the city center (Figure 11). Accident rates are much lower than the city average, while car ownership rates are relatively high.
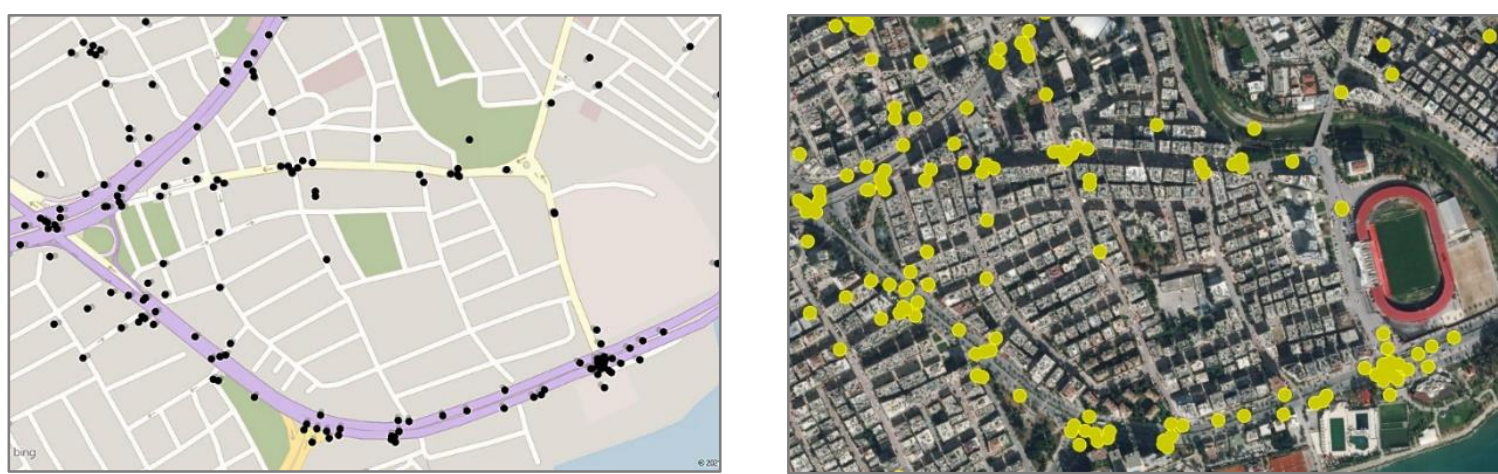

Figure 11 Street Network and Location of Accidents in Pirireis Neighborhood

Güneş is an unplanned neighborhood and has a rectangular but irregular grid street network (Figure 12). Local street widths range between 5-7 meters. Accident rates are pretty low (2.3) since the car ownership rate $(25 / 1000)$ of the poorest income groups residing in these neighborhoods is much lower than the city average (150). Street length per capita, which is 1.1 meters, is much less than the city average (1.7). Figures showed that although street length per capita is relatively low and streets and intersections are shaped in an irregular form, the neighborhood is much safer than the rest of the city, thanks to the low rate of car ownership. 

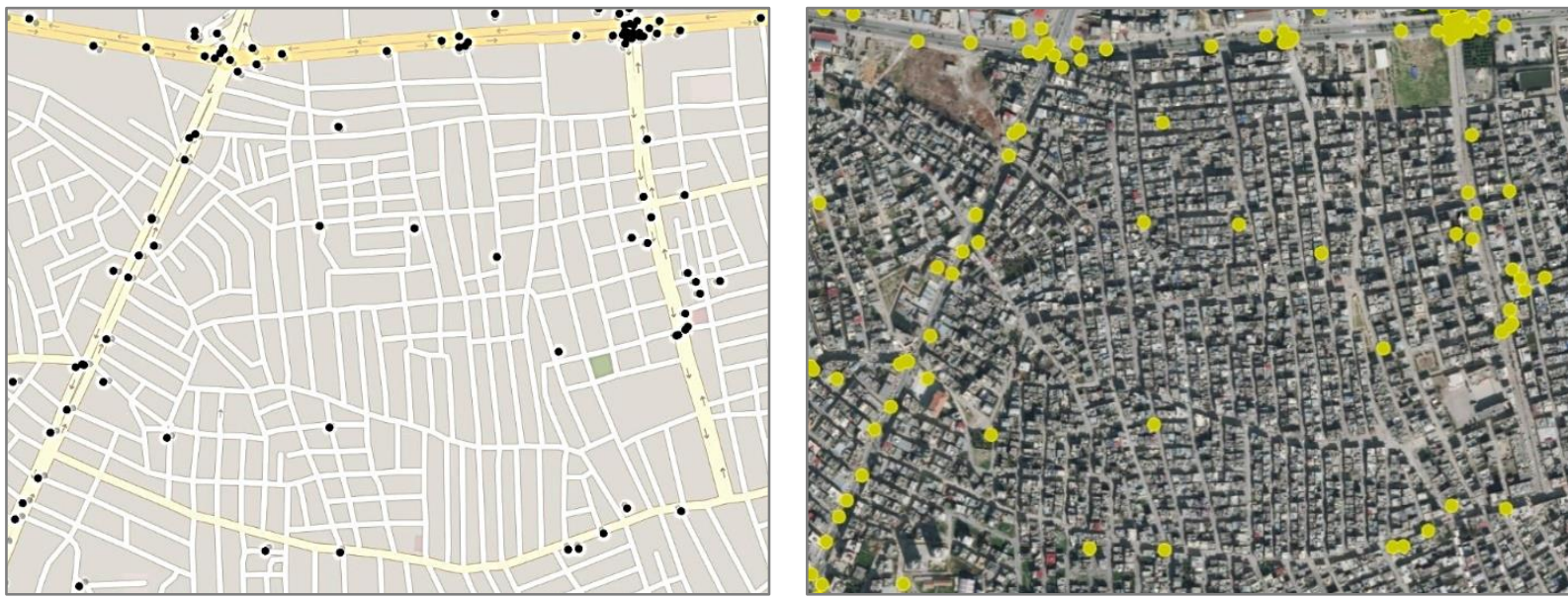

Figure 12 Street Network and Location of Accidents in Güneş Neighborhood

\section{Conclusions}

Research findings revealed that compared to residential neighborhoods, commercial and industrial uses generate more traffic; therefore, those land uses are responsible for higher rates of accidents. It is found that the number of vehicles and automobile ownership rate increases the accident rate. There was no significant correlation between street density and the number of accidents.

Model results reveal that street length per population reduces accident frequencies. Traffic safety cannot be achieved if the street length is not proportional to the number of vehicles. In addition, street design is also a matter of efficient use of urban space. On the other hand, the number of intersections increases the probability of accident occurrence. Empirical analysis showed that street length is proportional to population density in Mersin city. Another important influencing variable in the design of the street network is the car (automobiles) ownership rate, and hence number of cars per neighborhood. If the street length is proportional to the number of cars, accident rates can be reduced. Findings showed that the length of the street network is not proportional to the number of cars in the neighborhoods of Mersin city, and the accident rate is high in the neighborhoods where the number of vehicles is high and the street length is short. In order to achieve traffic safety, it is recommended that the street network can be designed not only proportional to the population density, but also proportional to estimated number of vehicles. It is expected that the street length per population will be higher in the neighborhoods where the number of automobiles is high and where the middle-high and high-income groups live. However, if residential areas are planned with high population density in neighborhoods where high automobile ownership rates are estimated, the share of the street area in the total neighborhood area will be very high. For this reason, it is recommended that residential areas can be planned and designed with lower population densities if automobile ownership is expected to be high.

In this research significant relationship between the intersection density (intersection per hectare) and the number of accidents was not found. Aggregate analysis at urban scale showed that $73 \%(1791 / 2554)$ of crashes occurred at intersections while $27 \%(663 / 2554)$ of them were observed at the roadside (street sections).

Figures reveal that some of the street network properties have a significant role in accident occurrence. In addition, pedestrian and driver profile, traffic control measures, intersection design, sight view weather conditions, seasonal factors, day and night timeline may have a significant role in accident occurrence. Further studies may employ Binomial Logistics Regression to obtain more detailed, reliable, and sensitive results. 


\section{References}

Boğaziçi Proje (2015), Mersin Transport Master Plan, Mersin Metropolitan Municipality.

Giacomin. D. J. \& Levinson. D. M. (2015). Road network circuity in metropolitan areas. Environment and Planning B: Planning and Design. 42(6). 1040-1053.

Haggett. P. \& Chorley. R. J. (1969). Network analysis in geography (Vol. 1). Hodder Education.

Háznagy. A. \& Fi. I. (2016). Comparing the road networks of residential areas. Pollack Periodica. 11(3). 61-72.

Kansky. K.J. (1963). Structure of Transportation Networks: Relations Between Network Geometry and Regional Characteristics (Unpublished PhD Thesis). University of Chicago.

Litman. T. (2005) Roadway connectivity: Creating more connected roadway and pathway networks. 20.9.2021 tarihinde http://www.vtpi.org/tdm/tdm116.htm adresinden erişildi.

Marshall. W. Garrick. N. (2010) Street network types and road safety: A study of 24 California cities. Urban Design International 15. 133-147. https://doi.org/10.1057/udi.2009.31

Marshall. W. E. \& Garrick. N. W. (2011). Does street network design affect traffic safety? Accident Analysis \& Prevention. 43(3). 769-781.

Özen. M. (2020). Dört Kollu Sinyalize Kentsel Kavşaklarda Trafik Kazalarının Sıklığını Etkileyen Faktörlerin Incelenmesi. Teknik Dergi. 31 (3). 10033-10053. DOI: 10.18400/tekderg.509128.

Sharifi. A. (2019). Resilient urban forms: A review of literature on streets and street networks. Building and Environment. 147. 171-187.

Soltani. A. \& Allan. A. (2005). A computer methodology for evaluating urban areas for walking. cycling and transit suitability: four case studies from suburban Adelaide. Australia. In Proceedings. 8th Computers in Urban Planning and Urban Management Conference.

Southworth. M. \& Ben-Joseph. E. (1995). Street standards and the shaping of suburbia. Journal of the American Planning Association. 61(1). 65-81.

Southworth. M. \& Ben-Joseph. E. (2013). Streets and the Shaping of Towns and Cities. Island Press.

Taylor. J. (2001) Transportation and community design: The effects of land use and street pattern on travel behavior. Technical Bulletin. 11:1-4. 21.9.2021 tarihinde http://www.jtc.sala.ubc.ca/bulletins/TB_issue_11_Transportation_edit.pdf adresinden erişilmiştir.

Zadeh. Where. M. \& Rajabi. M. A. (2013). Analyzing the effect of the street network configuration on the efficiency of an urban transportation system. Cities. 31. 285-297.

Zhang. M. (2013). On the Cul-de-Sac vs. Checker-board street network: Search for sustainable urban form. International review for spatial planning and sustainable development.1(1). 1-16.

\section{Resume}

Fikret Zorlu received his BSc. degree in City and Regional Panning from Middle East Technical University, Faculty of Architecture (1991-1996). Zorlu received his MSc, and Ph.D. degrees in City and Regional Panning from Middle East Technical University, School of Natural and Applied Sciences (1996-2006). Major research interests include urban transportation, city logistics and urban design. Zorlu has also conducted many research projects about urban design, urban transport and logistics. He contributed to published articles to many national and international publications and has received various awards in urban design and architectural design competitions. He teaches urban transportation, urban project management and planning studio courses at Mersin University. 